\title{
Language and Power: A Critical Discourse Analysis of the Political Speech
}

\author{
Tianqi Li and Yi Zhang
}

\begin{abstract}
Critical discourse analysis is a linguistic trend developed from the late 1970s to the early 1980s. Its source is critical linguistics. Representatives include mainly anti-mainstream linguistics and sociolinguists in the UK, France, and Germany, such as M. Fourcault, N. Fairchlugh, G. Kress, R. Fowler, and others. It is a socially oriented discourse analysis method based on Halliday's systemic functional linguistics. They see society as an organic whole, and all its components are a reflection of some kind of power.

This paper is devoted to study the interpersonal function of Donald Trump's and Teresa May's speeches from the perspective of critical discourse analysis by Systematic-Functional Grammar (SFG) established by M.A.K Halliday. The study reveals that political speakers tend to employ far more modal operators of medium value to realize interpersonal functions for political and power needs.

The critical discourse analysis of political speech not only contributes to the establishment of a different perspective of the discourse analysis but also helps to the cultivation of the critical thinking ability, which can shed light on the further studying and research.
\end{abstract}

Index Terms - Critical discourse analysis, modality, personal pronoun, political speech

\section{INTRODUCTION}

According to Fairclough [1], language is a kind of social practice. It is an eternal intervening force of social order. It reflects reality from all angles and manipulates and influences social process by reproducing ideology. In the social and cultural environment, there is an interactive relationship between language and values, religious beliefs and power relations.

The theory was introduced to China in the mid 1990s by Chen Zhongzhu. Then, more and more scholars started the research of this field, but most of whom only target on the introduction and explanation of the theory. And a few of them combined the theory with discourse analysis, but materials they chose are mostly news report [2].

There are also other scholars who pay attention to the combination of the theory with the political speech, such as the analysis of the political news [3]. It needs to be pointed that there is a considerable amount of researches targeting on the critical discourse analysis of the American president's campaign speech and victory speech [4].

As is mentioned above, plenty of researches have been conducted in the field. However, the CDA analysis of the

Manuscript received August15, 2019; revised September 17, 2019.

Tianqi Li and Yi Zhang are with the School of Foreign Studies, Northwestern Polytechnical University, China (e-mail: litianqi1221@ 163.com,2192941516@qq.com). foreign policy speech has far been scare. So, it's of importance to make a deeper analysis. In the paper, the author will use the theoretical framework of interpersonal functional grammar proposed by M.A.K Halliday to give a critical discourse analysis of the present American president---Donald Trump's first foreign policy speech in the UN. This research is intended to fill the gap, so as to give a detailed analysis of Trump's speech and make the application of CDA more comprehensive.

In order to give a critical discourse analysis of Donald Trump's and Teresa May's speeches, this study selects Trump's Speech to the 72nd Session of the United Nations General Assembly and May's Speech on 2018 G20 Summit, which are both political speeches with great significances. The main purpose of this study is to investigate how modality and person system are used by the speaker to achieve his political purposes and needs. The quantitative analysis is to show the statistical research results while the qualitative analysis aims to give a critical discourse analysis of the results. The following are research questions this study aims to answer.

1. How the interpersonal function is used to achieve the speaker's political purpose?

2. What the political view the speaker intends to convey through the language?

\section{DISCUSSION}

\section{A. Research Background}

On January 25, 2019. British Prime Minister Teresa May attended and delivered a speech at the annual meeting of the World Economic Forum in Davos, Switzerland. In her speech, she expressed Britain's support for free trade and the global rule system, and believed that it should continue to be promoted to ensure that all parties benefited from it. On September 19, 2017, American president Donald Trump made a speech to the 72nd Session of the United Nations General Assembly. This is his first time to clearly demonstrate the U.S. diplomatic stance to the international community. Moreover, he clearly states the "U.S. first" policy and calls on the United Nations to unite the sovereign states to solve the world's problems. The discussion will explore the interpersonal function of their language from the perspective of CDA.

In linguistics, modality is a feature of language that allows for communicating things about, or based on, situations which need not be actual. More precisely, modality is signaled by grammatical expressions (moods) that express a speaker's general intentions (or illocutionary point) as well as 
the speaker's commitment to how believable, obligatory, desirable, or actual an expressed proposition is [10].

When it comes to the choice of specific modal verbs to express the attitude, the interpersonal function of modal verbs should be taken into consideration, because modal verbs of different values can express different interpersonal functions. The choice of modal verbs between high, medium and low can be seen as the choice of interpersonal functions of modal verbs.

These two speeches include 5105 words in total, in which 78 modal verbs are used. The percentage of modal verbs account for $1.5 \%$. The use of specific modal verbs are shown in Table I.

TABLE I: THE USE OF MODAL VERBS IN THE SPEECH

\begin{tabular}{lllllll} 
Modals & will & can & must & would & should & could \\
\hline Frequency & 28 & 21 & 17 & 7 & 3 & 2
\end{tabular}

From Table I, it can be found that "will" is the most frequently used modal verb, with 28 in number, the next are "can" and "must", with 21 and 17 respectively. From the perspective of the level, it can be indicated that modals of medium value accounts for the largest number, with $48.7 \%$ in the percentage, and both high and low are $51.3 \%$ in the percentage.

It's Teresa May's International debut, where she is supposed to represent a responsible great power. Moreover, it's a special time when Britain is still in the process of leaving EU. So, she is guarded with her speech in the choice of words. In terms of the other speech, it's also the first time that Trump give the speech to United Nations, so he is cautious with words to not only express his "America First" foreign policy, but also to persuade other nations to collaborate with the United States. Moreover, the international situation is still complicated and unclear. So, he choose more modal verbs of medium value to win the support of the audience in a mild and moderate way, which contributes to the achievement of his political purpose. Considering that "will", "can" and "must" are three most frequently used modal verbs, detailed analysis will be given in the following part. In terms of the high frequency of "will", "can" and "must", the detailed analysis will be conducted in the following.

\section{B. Analysis of Modality}

The word "will" is the most frequently used modal verb in the speech. Here is an example: "And for the first time in more then four decades the UK will have an independent trade policy, playing an active role on the global stage as we take up our seat at the WTO in April 2019."

In Teresa May's Speech, "will” is adopted to illustrate an positive image of Britain to the world that UK will be more independent and shoulder more responsibilities when it can make a voice at the WTO independently.

The similar use of "will" can also be found in Trump's speech.

"The United States will forever be a great friend to the world, and especially to its allies. But we can no longer be taken advantage of, or enter into a one-sided deal where the United States gets nothing in return. As long as I hold this office, I will defend America's interests above all else."

The first "will" is used as a commitment to America's allies, trying to build a responsible image of great powers to the world. Different from the first commitment to the outside world, the second "will" can be taken as a promise to its own citizens, which corresponds to "America first" foreign policy.

Another example is Trump's depiction of those "rogue" countries. Here is an example: "If the righteous many do not confront the wicked few, then evil will triumph. When decent people and nations become bystanders to history, the forces of destruction only gather power and strength." Here, he tries to use "will" to illustrate the seriousness of those "threats", the purpose of which is to unite as many countries as possible to combat those "threats".

Besides the above examples, there is also another one that is typical for the detailed analysis. "Oppressive regimes cannot endure forever, and the day will come when the Iranian people will face a choice. Will they continue down the path of poverty, bloodshed, and terror? Or will the Iranian people return to the nation's proud roots as a center of civilization, culture, and wealth where their people can be happy and prosperous once again?"

The first two "will" are used to encourage its allies and discourage the combatants who are opposed to the interference of America. The following two "will" can be regarded as a further persuasion to those "combatants", trying to use the comparison of the wealth and poverty to unite it into the allies of America.

Different from "will", "can" is a modal verb of low modality value, which indicates the meaning of the ability or the possibility. Some examples are cited for the detailed exploration of the use of "can" in the speech.

Here is an example from Teresa May's speech: "We also welcomed the agreement on a new commercial air link between the Falklands and S ao Paulo via Córdoba, a move that shows what we can achieve when we work together."

In this example, the modal "can" is used to express the meaning of capability. Here, she is intended to indicate that Britain is delighted to work with other countries though both the British and International situation is changing rapidly. The modal "can" here helps to transfer her wish to seek the International cooperation.

Another typical example is from Trump's speech, here is the passage:

"As long as I hold this office, I will defend America's interests above all else. But in fulfilling our obligations to our own nations, we also realize that it's in everyone's interest to seek a future where all nations can be sovereign, prosperous, and secure." "Can" here signifies the meaning of the possibility. Because of the occasion of the speech and the status of America, Trump tries to use the illustration of the bright future to call for actions and responsibilities of all nation. "Can" is used to make the request more indirect and euphemistic, which can be more easily accepted by the audience.

Here is another example: "We will slide down the path of complacency, numb to the challenges, threats, and even wars that we face. Or do we have enough strength and pride to confront those dangers today, so that our citizens can enjoy 
peace and prosperity tomorrow?" The modal "can" in this example indicates the meaning of ability. The speaker conveys that the peace and pride of the future generations are based on the effort to strike those dangers. So, the modal here can be seen as an indirect calling for countries to stand with American allies.

The third modal verb which is typically used in the speech is "must", which ranks high in the classification of modality value. Here is an example: "To overcome the perils of the present and to achieve the promise of the future, we must begin with the wisdom of the past." The high value word "must" is used here to strengthen the expression of emotions of the speaker. Trump indicates that the problems nowadays can be tackled with regards to the solution of Marshall Plan. The modal verb here can be regarded as a strong belief and persuasion of America's plan.

There is also another significant use of "must" in the speech. Here is the example: "We must protect our nations, their interests, and their futures. We must reject threats to sovereignty, from the Ukraine to the South China Sea. We must uphold respect for law, respect for borders, and respect for culture, and the peaceful engagement these allow." In this excerpt, the speaker uses three "must" in succession to show his determination to the solution of the present problems. Here, as a president, Trump not only makes a promise to its own citizens, but also calls for the unity of its allies and some other countries. The third "must" is especially interesting for the analysis. After the reference to threats in Ukraine and South China Sea, Trump intentionally uses "must" to criticize those countries which are taken as "threats" to America in the world.

According to Halliday [5], the meaning of modality lies between right and wrong, between affirmation and negation, reflecting the speaker's stance on an idea or proposal, and representing the speaker's attitude, viewpoint and opinion on the statement. Halliday [6] categorizes modality according to the speaker's validity of an idea or proposal, and the speaker's determination to carry out a proposal or request and assume certain responsibilities. The use of low-valued modal verb "can" indicates that Trump tends to communicate in an approachable way, which can effectively shorten the distance between the speaker and the audience. The medium-valued "will" is used for expressing willingness and prediction. The speaker frequently uses "will" to attract the audience through the high level of involvement of the speaker.

\section{Analysis of Personal Pronoun}

Halliday puts forward that "interpersonal meanings are also embodied in the personal system, not only as pronoun but also as possessive. They represent the world on the basis of the speaker in the context of a speech exchange. For example, the item "you" indicates the listener; "I" or "we" represents the speaker [6].

According to Halliday, the personal system is "one realization of the interpersonal meaning" [7]. "It's of influence to use personal pronouns directly involving the listener in the discourse situation, appealing directly to his or her knowledge, interests and emotions, when the text in the advertisement is apparently a monologue" [8]. The use of personal pronouns in two speeches is shown in Table II.
TABLE II: THE USE OF PERSONAL PRONOUNS

\begin{tabular}{|c|c|c|c|c|c|}
\hline & First PP & & Second PP & Third PP & \\
\hline $\begin{array}{l}\text { Persona } \\
1 \\
\text { Pronou } \\
n\end{array}$ & $\mathrm{I}, \mathrm{me}, \mathrm{my}$ & $\begin{array}{l}\text { we, us, } \\
\text { our, } \\
\text { ourselves }\end{array}$ & you, your, & $\begin{array}{l}\text { his,her,h } \\
\text { imself, }\end{array}$ & $\begin{array}{l}\text { they, the } \\
\text { m,their, } \\
\text { themsel } \\
\text { ves }\end{array}$ \\
\hline Frequen & 28 & 185 & 9 & 9 & 77 \\
\hline
\end{tabular}

cy

Personal pronouns are used for 308 times in the speech, which accounts for $6.03 \%$ in the speech. The second person pronoun occurs for the least, with only 9 times in the speech, which mainly refer to the audience in the conference. For example: "Thank you. God bless you."

The first person pronouns are used for the most in the speech, with the number much bigger than those of second and third person pronouns [8]. The first person singular appears 28 times, which refer to the speaker himself. The first person plural occurs 185 times, with the reference to the various group of people. Regarding the high frequency of the first person pronoun, the detailed analysis will be conducted in the following.

"I" occur mainly in the following examples. (1) I want to begin by expressing my appreciation to every leader in this room who has offered assistance and aid. (2) Like them, I intend to address some of the threats before us today but also the enormous potential waiting to be unleashed. (3) I was elected not to take power, but to give power to the American people, where it belongs. (4) As President of the United States, I will always put America first, just like you, as the leaders of your countries will always, and should always, put your countries first.

As the first person singular, "I" refers to the speaker, who is Trump himself. In general, the speaker of the political speech rarely uses the first person singular, because the speaker represents a certain party, government or a nation to convey the information, so the speaker tends to use "we" instead of "I" in the political speech. The purpose of this speech is to seek the support of more nation to stand in line with America, so the speaker intends to use the first person singular to shorten the distance between him and the audience, which is a craft way to persuade the audience to accept his opinions. Also, it can be found from the example that the image of a responsible president is depicted by the use of "I."

In May's speech, "we" is also often used. For example: "As well as discussing bilateral relationships and regional and global security issues this Summit has given me the opportunity to update friends and partners on the agreement we have reached on our exit from the European Union - and I have set out how it represents a good deal for the global economy."

In this segment, "we" is used to echo friends and partners she has mentioned. The craft use of this personal pronoun combined with other kind address can help to shorten the relationship between Britain and other countries, so as to establish a good image of UK and leave a positive impression on other countries.

\section{CONCLUSION}

From the discussion, it can be found that linguistic features 
serve for the social functions of the language. In this kind of political speech, the language is determined by the political aims at a certain time and in a certain social context [11]. The ideologies and political attitudes are reflected through the language, and language in turn has helped to strengthen these ideologies, which shows the dialectical relationships between language and ideology. In the discussion, it can be concluded that how the speaker expresses his ideas, beliefs or attitudes by the choice of the modal verbs.

Critical discourse analysis provides us with a different perspective to study the political discourse [9]. To explore the relationship between discourse and social factors of the discourse is to find out how the discourse is produced like that and why the discourse is presented in that way, which is the final aim of Critical discourse analysis. And that helps us have a better and deeper understanding of the discourse.

\section{ACKNOWLEDGMENT}

I would like to deliver my gratefulness to those who have offered me support during the process of this research, First, I would like to thank my supervisor, Professor Zhang Yi, without her guidance and encouragement, I couldn't finish this paper. Second, I am greatly indebted to the School of Foreign Studies, Northwestern Polytechnical University. Finally, my special thanks go to my beloved families and friends, who often share my worries and happiness together.

\section{REFERENCES}

[1] N. Fairclough, Critical Discourse Analysis, London: Longman, 1995.

[2] Z. Z. Chen "Discourse and ideology: Critical discourse analysis of two strike news," Foreign Languages Research, no. 3, 1995.

[3] Z. Z. Li, Interpersonal Meaning in Discourse, Shanghai: Shanghai Foreign Studies Press, 2002.

[4] D. Graber, "Styles of image management during crises: Justfying press censorship," Discourse \& Society, no. 5, May 2003.

[5] M. A. K. Halliday, An Introduction to Functional Grammar, Beijing: Foreign Language Teaching and Research Press.
[6] T. Givon, Functionalism and Grammar, Amsterdam: J. Benjamins, 1995.

[7] R. Hodge and G. Kress, Language as Ideology, London: Routledge, 1993.

[8] R. Wodak, Language, Power and Ideology, Amsterdam: John Benjamins, 1988.

[9] R. Wodak and M. Meyer, Methods of Critical Discourse Analysis, London: SAGE Publication Ltd, 2001.

[10] R. Clark and R. Ivanic, "Raising critical awareness of language," Language Awareness, 1999.

[11] B. Xin, "Language, text and power," Foreign Languages Research, no. 4, 2003.

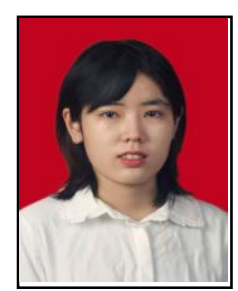

Tianqi $\mathbf{L i}$ is a graduate student in School of Foreign Studies, Northwestern Polytechnical University, Xi'an, Shaanxi Province, China, who was born on December $12^{\text {th }}, 1994$ and got her bachelor degree of arts in Chang'an University, Xi'an, Shaanxi Province, China in 2017.

She focused on the investigation of stance in academic field and published a related article in advance research on multidisciplinary discoveries. She was invited to give oral presentations of her research in several international conferences, including the $17^{\text {th }}$ Asia TEFL and the $8^{\text {th }}$ L3 Conference.

In 2016, she took a two-week teaching internship, teaching college English course to freshmen major in civil engineering, Chang'an University.

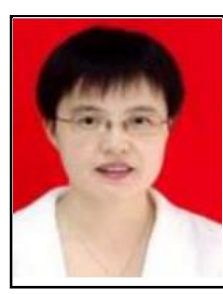

Yi Zhang is a professor in School of Foreign Studies, Northwestern Polytechnical University, Xi'an, Shaanxi Province, China, who got the MA of applied linguistics in Northwestern Polytechnical University in 2006, and her BA degree of English in Shaanxi Normal University in 1999.

She published numerous research articles in high-level journals at home and abroad. She led several research projects, including "Research on Public Video of Space Material Science", funded by Chinese National Natural Science Foundation, 2013-2014.

She had several social appointments. She is a councilor member of Chinese Educational Linguistic Association; Member of Asial TEFL and Anonymous Reviewer of International Journal "Linguistics and Literature Studies". 